\title{
POTENCIAL DE BLASTOSPOROS DE Metarhizium anisopliae PARA O CONTROLE DE ADULTOS DE Aedes aegypti
}

\author{
Aline Teixeira Carolino ${ }^{1}$ \\ Simone Azevedo Gomes ${ }^{2}$ \\ Thais Berçot Pontes Teodoro ${ }^{3}$ \\ Richard lan Samuels ${ }^{4}$
}

Resumo: Os conídios do fungo entomopatogênico Metarhizium anisopliae são capazes de infectar desde o ovo até a fase adulta do mosquito Aedes aegypti. Em cultura líquida, fungos entomopatogênicos são capazes de produzir blastosporos, um propágulo com características hidrofílicas e às vezes mais virulento que conídios. No presente estudo foi observado pela primeira vez, que blastosporos secos quando formulados em óleo são eficientes para controle do mosquito adulto. Foi observada somente $1 \%$ de sobrevivência dos mosquitos tratados com blastosporos e 94\% de sobrevivência do grupo controle. Estudos já evidenciaram que formulações em óleo podem melhorar a eficiência de fungos entomopatogênicos durante o processo de infecção, facilitando a adesão do mesmo com o tegumento dos insetos. Pelo fato dos blastosporos serem hidrofílicos, a película formada pelo óleo ao redor do fungo, favorece a interação entre o fungo e o inseto, levando à infecção dos adultos.

Palavras-chave: Mosquito; Fungo entomopatogênico; Controle microbiano; Virulência.

\footnotetext{
${ }^{1}$ Ciências Biológicas/Universidade Estadual Norte Fluminense, Brasil. E-mail: carolinoat@gmail.com.br.

2 Ciências Biológicas/Universidade Estadual Norte Fluminense, Brasil. E-mail: simoneazgomes@yahoo.com.br.

${ }^{3}$ Ciências Biológicas/Universidade Estadual Norte Fluminense, Brasil. E-mail: thaisbercot@yahoo.com.br.

${ }^{4}$ Zoologia/Universidade Estadual Norte Fluminense, Brasil. E-mail: richardiansamuels@gmail.com.
} 